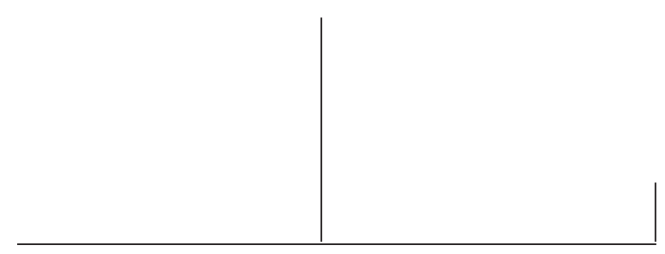

Rev. Latinoam. Psicopat. Fund., X, 2, 319-331

\title{
A clínica da psicose no campo da saúde mental: transferência e desejo do analista
}

\author{
Gabriela Rinaldi Meyer
}

\begin{abstract}
O presente artigo procura refletir sobre a clínica da psicose no campo da saúde mental pelo viés da transferência e do que Lacan chamou de desejo do analista. Para isto, são trabalhados fragmentos de dois casos clínicos atendidos numa instituição de saúde mental, o CAPS Clarice Lispector, situado no município do Rio de Janeiro, no território do IMAS-Nise da Silveira. A partir da análise dos dois casos apresentados, a discussão do trabalho gira em torno de uma reflexão sobre a clínica da psicose no contexto institucional e sobre o lugar ocupado pelo psicanalista nesta clínica.
\end{abstract}

Palavras-chave: Clínica da psicose, transferência, desejo do analista, instituição 


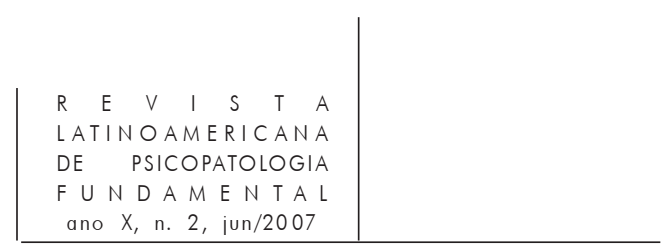

A clínica da psicose, a par de ser instigante e atraente, é portadora de dificuldades tão grandes que podem ser chamadas de impasses. Estes a constituem intrinsecamente, garantindo sua especificidade e sua diferença, ao mesmo tempo em que, paradoxalmente, promovem sua realização. Apresenta obstáculos à primeira vista suficientes para desencorajar os praticantes, o que fica evidente quando observamos o discurso de muitos psicanalistas ao colocarem em dúvida sua possibilidade de realização.

Freud manifesta interesse em refletir sobre ela, enunciando, contudo, na maioria das vezes, as dificuldades que a transferência apresenta neste caso, configurando um obstáculo determinante à sua realização. Como indica Allouch (1997), não é possível pensar a transferência na psicose com base exclusivamente na teoria freudiana, pois ele criou a psicanálise desenvolvendo o conceito de transferência a partir da neurose, e não teria sentido adaptarmos tal conceito para a psicose, pois trata-se de uma estrutura clínica marcada por outra lógica, outra organização. Reconhecer a psicose como uma estrutura originalmente diferente da neurose significa um avanço para o desenvolvimento de sua clínica, o que foi possível com Lacan e com o que ele trouxe de contribuição para este campo.

A orientação de Lacan a não recuarmos diante desta clínica nos conduz à reflexão sobre as particularidades da transferência que nela se apresentam. Constatamos que a transferência na psicose evidencia uma intensidade diferente em relação à forma como se manifesta na neurose. Ao se instaurar, apresenta-se freqüentemente de forma maciça, o que certamente traz dificuldades para o trabalho clínico. A partir dos casos que serão examinados pretendemos pensar como o dispositivo transferencial, fundamental para qualquer clínica, pode ser sustentado nesta clínica específica, o que nos leva a articulá-lo àquilo que Lacan designou como desejo do analista.

Na clínica da psicose, observamos que a demanda de tratamento não parte, na maioria das vezes, do sujeito e sim do outro (semelhante). Quando é possível ao sujeito apresentar alguma demanda, ela se mostra, 


\section{SAÚDE MENTAL}

ano $X$, n. 2, jun $/ 2007$

em diversas situações, sob a forma de um pedido de afirmação de existência, o que coloca o psicanalista em um lugar especial, diferente do que ocorre na clínica da neurose: aquele de acompanhar o sujeito na construção de uma forma de existência que o sustente. A posição do psicanalista, assim, através de sua presença e de seu desejo é fundamental e determinante.

Ao refletir sobre o desejo do analista, nos perguntamos: afinal, o que vem a ser o desejo do analista? Antes de tudo, é necessário dizer que, como todo desejo, é um desejo articulado ao campo do Outro - é um desejo do Outro. Mas não se trata de um desejo pessoal e sim de uma função que se relaciona à posição que o psicanalista ocupa na relação analítica. Pretendo investigar como pode ser pensada a articulação entre a transferência e o desejo do analista na clínica da psicose a partir da hipótese de que é o desejo do analista investido de uma condição especial que pode viabilizar a transferência com todas as particularidades aí presentes.

No Seminário 11, sobre Os quatro conceitos fundamentais da psicanálise (1964), Lacan trabalha a noção de sujeito suposto saber como base da transferência, sustentando a íntima relação entre o lugar de sujeito suposto saber atribuída ao analista e a busca do desejo inconsciente. $\mathrm{O}$ analista é suposto saber partir ao encontro desse desejo. Neste sentido, o desejo é o eixo do que se formula, inicialmente, como demanda no discurso do paciente, ou seja, a própria transferência. O desejo do analista tal como o apresenta Lacan nesse Seminário, é o que está por trás dessa demanda, justamente o ponto comum entre o desejo do paciente e a transferência.

Na clínica da psicose, o que deve ser questionado é justamente essa suposição de saber como suporte da transferência, pois a crença delirante de que o Outro sabe e, portanto invade o sujeito, obriga-nos a repensar a função do sujeito suposto saber na direção clínica deste trabalho. Foi Lacan quem enfatizou o saber do sujeito psicótico quando no Seminário 3, sobre As psicoses (19551956), nos convidou a ser secretários do alienado, a acompanhar o sujeito a partir da escuta de sua fala, do saber da diferença que caracteriza o discurso do sujeito psicótico. Como indica Zenoni (2000), esta posição é favorável para encontrar um sujeito que sabe, que é ele mesmo a significação do que lhe é endereçado enigmaticamente. Tal saber não é suposto, mas realizado pelo próprio sujeito.

Foi, mais precisamente, o saber delirante que se caracteriza como certeza, pois não abre espaço para ser questionado, que fez com que Lacan se encantasse com Marguerite, mais conhecida pelo nome fictício Aimée, caso sobre o qual se debruçou em sua tese de doutorado. Allouch (1997), ao refletir sobre o lugar do psicanalista na clínica da psicose, retoma a tese de Lacan valorizando a idéia de que a transferência nestes casos apresenta-se inicialmente do lado do analista é uma transferência para com o psicótico - sendo este o fator preponderante para 


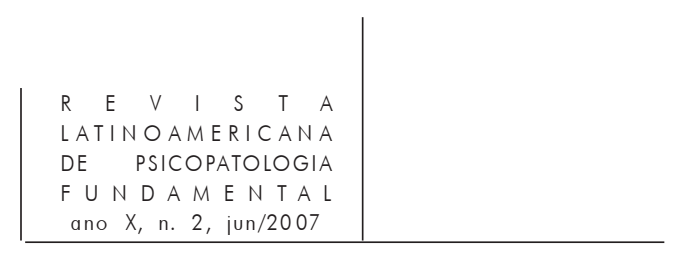

a realização da clínica. Tal transferência aponta para o desejo do analista e podemos pensá-la como relacionada a uma posição de não-saber que abre espaço para o saber do sujeito.

Para melhor esclarecer tais questões e enriquecer a discussão em torno delas serão apresentados fragmentos de dois casos clínicos que se desenvolveram numa instituição de saúde mental do Município do Rio de Janeiro, o CAPS ${ }^{1}$ Clarice Lispector (antigo Centro de Convivência) que nasceu dentro do IMAS ${ }^{2}$ Nise da Silveira com o objetivo de construir uma nova forma de atenção e tratamento para psicóticos e neuróticos graves.

\section{Caso Ana}

Ana é uma moça de mais ou menos 28 anos que chegou para atendimento após viver sua primeira internação em virtude de uma crise que culminou com uma tentativa de suicídio. Veio ao CAPS trazida por sua sogra que assumira os cuidados de Ana e sua filha. É importante chamar atenção aqui para o fato de que Ana não desejava ser tratada, mas, diante da grave situação em que se encontrava, não teve outra alternativa e acabou por aceitar ser cuidada e tratada. Apesar de não resistir ao tratamento, pois não estava em condições de controlar sua própria vida, foi muito difícil para ela entrar em alguma forma de tratamento e conseguir falar sobre seu sofrimento ou sobre a ausência de sofrimento, já que se apresentava de forma apática, sem vida e sem motivos para viver. Ela representava o próprio vazio e isso era muito difícil de suportar. Difícil também para mim, a psicanalista que a acolheu desde a entrevista de recepção, e sustentou desde então um lugar de suporte para esse vazio, que definia, nesse momento, a condição de Ana.

Ana iniciou seu tratamento na "oficina da palavra", uma das atividades do CAPS, coordenada por mim, onde escutava o discurso dos outros e pouco falava de si, parecendo não se sentir à vontade para falar de seus problemas no meio de tanta gente. Acabou por me pedir que a atendesse individualmente. Penso que ao dirigir esse pedido a mim, algo de um laço transferencial já se ensaiava. Ao começar os atendimentos pouco falava, sempre afirmando não ter muita coisa a dizer sobre sua vida, deixando claro o esvaziamento em que se encontrava. Aos poucos foi deixando claro que não queria estar ali, pois era muito reservada,

1. Os CAPS surgiram a partir do movimento da Reforma Psiquiátrica como serviços substitutivos aos Hospitais Psiquiátricos.

2. Instituto Municipal de Assistência à Saúde - antigo Centro Psiquiátrico Pedro II. 


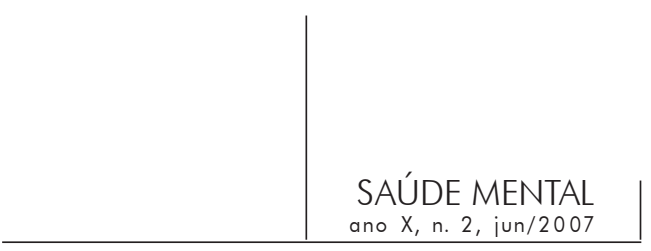

voltada para dentro, não gostava de falar de si. Vinha por insistência da família, sempre trazida por alguém. Se a demanda inicial não partiu de Ana, mas do outro (semelhante), o pedido para ser atendida individualmente já indicava um esboço de um vínculo.

Foi por grande insistência da psicanalista que Ana continuou freqüentando os atendimentos, pouco falando, mas falando algo. A analista estava sempre ali, naquele espaço, sustentando a aposta de que Ana não era só o vazio que trazia, que tinha, sim, algo dentro dela que em algum momento iria aparecer. Esta posição aponta para o lugar que o analista assume na escuta do vazio, da desamarração que traz a psicose. Um lugar muito difícil de ser sustentado, pois acena para a impotência do psicanalista no trabalho com psicóticos. É preciso uma abertura e uma disponibilidade para acolher o vazio existencial do sujeito, a partir de uma posição de um não-saber, que implica saber esperar o tempo do sujeito. A situação poderia levar o psicanalista a tentar quebrar esse vazio com o seu saber. Contudo, o desejo do analista o conduz a um lugar vazio que está intimamente ligado à posição de não-saber de sua parte, sustentando uma posição que promova a instalação da transferência.

Neste momento cabe esclarecermos a diferença entre demanda e desejo, tal como formulada por Lacan, para ajudar a pensar o que se passou no caso Ana. Em "A significação do falo" (1958) Lacan define demanda como algo distinto das satisfações por que clama, trata-se de "demanda de uma presença ou de uma ausência", ou seja, algo distinto do que poderíamos chamar de necessidade. A demanda situa-se no registro da relação do sujeito com a linguagem, o que define um desvio das necessidades do homem justamente pelo fato de ele estar na linguagem. Neste sentido, ela pode ser pensada como sendo uma espécie de estágio inicial do desejo que se localiza para além da demanda. O desejo, apesar de estar para-além dela, mantém uma relação com a demanda, na medida em que ela o veicula. O que marca sua diferença, no entanto, é que o desejo é irredutível à demanda, não se esgotando nela. Refletindo sobre a clínica de forma geral, e sobre a transferência, para que esta se instale é preciso que exista uma demanda. Ao analista não cabe satisfazer, atender à demanda, o que pode inviabilizar o surgimento do desejo do sujeito, mas acolher o sujeito, o que pode abrir portas para o que está para-além dela, o desejo. Em relação à clínica da psicose, observamos que a demanda surge de forma diferente. No caso de Ana, inicialmente, parecia não existir uma demanda propriamente dita; chegou ao CAPS trazida pela família por conta da grave e profunda crise de depressão vivenciada. Isso, contudo, não era suficiente para lhe fazer falar, demandar algo. Neste sentido, a presença da analista e a aposta de que em algum momento a demanda pudesse vir a surgir, foram fundamentais para que Ana começasse a falar. 


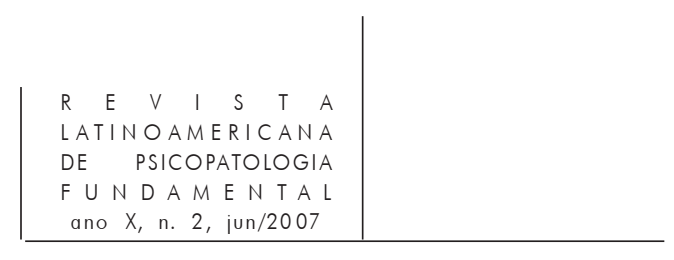

O lugar assumido pela psicanalista permitiu alguma modificação na posição de Ana em relação à sua vida. Sua aposta numa possibilidade de tratamento indica o modo como se instalou a transferência e como a analista foi incluída nela: diante de uma ausência de demanda faz-se necessária a oferta de um espaço de escuta e acolhimento do sujeito na sua condição, sustentada pela presença do analista. Foi deste modo que se deu a constituição do que vamos chamar mais adiante de desejo do analista. Brincando com as palavras de Lacan podemos dizer que inicialmente não se instalou uma demanda de presença ou de ausência, mas sim uma ausência de demanda, o que fez com que a analista se abrisse para a transferência pautada por tal referência.

Introduziremos em seguida alguns fragmentos do segundo caso clínico acompanhados dos devidos desdobramentos.

\section{Caso Vítor}

Vítor chegou para atendimento no CAPS encaminhado pela equipe do ambulatório central do IMAS-Nise da Silveira. Inicialmente, ainda adolescente, fora acolhido pelo serviço de atendimento à infância e adolescência que se situa dentro do IMAS, onde permaneceu em tratamento por alguns anos. Ao completar 18 anos foi encaminhado para o ambulatório onde foi atendido por alguns psiquiatras e psicólogos. Todas as equipes de profissionais que estiveram à frente do caso relataram a desesperança em conseguir que Vítor se vinculasse a alguma forma de tratamento; apesar de estar "há anos" "vinculado" a tais instituições, segundo esses relatos, ele nunca efetivamente se tratou - no sentido estrito da palavra não tomava a medicação, não participava das oficinas terapêuticas e nem de um atendimento terapêutico individual. Tal situação chegou a um ponto em que o psiquiatra e a psicóloga responsáveis por seu tratamento no ambulatório encaminharam-no para o CAPS com a expectativa de estabelecer uma parceria, na tentativa de construção de alguma forma de tratamento para Vítor.

Construir alguma forma de tratamento... essa frase nos faz pensar sobre o que isso significa no caso da psicose, em que a construção deve partir dos possíveis caminhos indicados pelo próprio sujeito. Em relação ao caso Vítor, essa reflexão se dá num tempo posterior, tempo já de escrita do caso. Na época em que o caso nos foi encaminhado ainda não era possível fazer tal reflexão.

Vítor foi apresentado ao CAPS como um caso muito grave de heteroagressividade, que culminou com uma agressão à sua avó, provocando-lhe um traumatismo craniano. Ao ser descrito como uma pessoa extremamente agressiva, manipuladora e avessa a qualquer forma de contato, ficou claro o sinal 


\begin{tabular}{l|l} 
& $\begin{array}{r}\text { SAÚDE MENTAL } \\
\text { ano X, n. 2, iun/2007 }\end{array}$ \\
\hline
\end{tabular}

de desesperança e de pouca aposta no caso. A suposição diagnóstica descrita nos prontuários indicava uma possibilidade de psicopatia. Até aquele momento Vítor havia tido cerca de vinte internações - essa foi a única forma de tratamento vivida por ele, se é que podemos chamar internação de tratamento. Todas as vezes em que foi internado nada de diferente se produzia, na maioria das vezes ele fugia ou tinha alta, mas voltava em pouco tempo a ser internado novamente. Ele foi, durante todo esse tempo, um exemplo vivo do que representou o tratamento da loucura antes dos ventos da reforma psiquiátrica soprarem pelo Brasil.

Consideramos importante introduzir parte da história de Vítor numa tentativa de entender um pouco do caso, através de seu lugar ou falta de lugar no contexto familiar. Esta história pôde ser recolhida a partir da fala da mãe. Começamos, assim, a conhecer um pouco de seu lugar na relação familiar, o que foi fundamental para entendermos parte de sua história de adoecimento. Ele é o segundo filho de uma prole de dois - nasceu em um momento em que o pai, segundo a mãe, não queria mais filhos. A mãe engravidou e teve Vítor à revelia do pai, que não foi consultado para tal projeto. A forma como a mãe se refere ao pai indica seu lugar "apagado" na família - o que não tem voz ativa. Paralelamente, a maneira como a mãe se refere a Vítor evidencia o possível lugar ocupado por ele em sua vida, lugar de objeto, o que foi se esclarecendo ao longo de seu relato.

Foi em torno dos 12, 13 anos que Vítor foi internado pela primeira vez, "porque estava muito agressivo e subiu no telhado, varando as telhas lá de cima" (sic). O Corpo de Bombeiros foi chamado e levou-o para o atual IMAS-Nise da Silveira, antigo Centro Psiquiátrico Pedro II, onde ficou internado no serviço que trata de crianças e adolescentes. Assim iniciou-se sua inserção psiquiátrica, que ocupou grande parte de sua vida. Depois dessa internação vieram muitas outras, que marcaram sua adolescência. Foi por essa ocasião que recebeu o diagnóstico de "esquizofrênico", o que determinou para ele um destino diferente dos outros jovens. Esse fato foi decisivo, pois tal diagnóstico lhe foi transmitido, marcandoo de forma definitiva, como se ele não pudesse ser outra coisa. Esse acontecimento nos dá uma indicação de como pensar os caminhos a seguir no trabalho com o psicótico - tal conduta, ao invés de abrir portas, fechou-as.

Ao recebermos o caso, a idéia, de imediato, foi nos unirmos à equipe do ambulatório no acompanhamento do atendimento familiar, que havia sido iniciado há pouco tempo. A pergunta que podemos fazer é: Por que iniciarmos o tratamento de uma pessoa via o acolhimento da família? A princípio, avaliou-se que o atendimento familiar poderia ser uma das formas de aproximação a Vítor, já que a notícia que recebíamos dele era de que não queria, de forma alguma, se tratar. Como as notícias que tínhamos sobre a família indicavam sua desestruturação, chamando a atenção em especial a posição da mãe, acolher o pedido de ajuda desta família pareceu fundamental como um primeiro passo. Fui designada, assim, para 


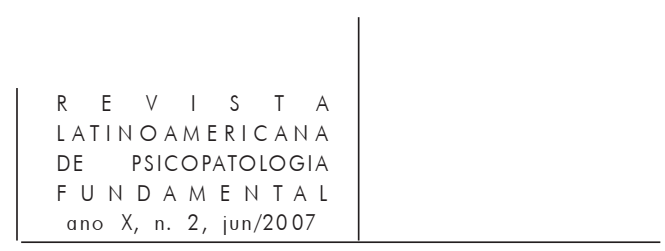

compor a equipe que participaria desse trabalho, assumindo o lugar de terapeuta de referência do caso.

O trabalho iniciou-se por ocasião de uma das internações de Vítor, o que propiciou que ele se aproximasse do CAPS, já que sua internação, na maioria das vezes, realizava-se em uma das enfermarias de atendimento à crise, localizada no IMAS, próximo ao CAPS. O objetivo do atendimento à família era promover um lugar de escuta para os pais, a partir da relação com o filho, numa tentativa de resgate das histórias de cada um. Com isso apostávamos que, pela fala, algo pudesse se deslocar nas relações entre eles, propiciando a abertura de novas possibilidades de existência para Vítor no seio familiar.

A partir do que foi se desenrolando nos atendimentos, foi se percebendo a dificuldade de inserção deste filho na família e de sua convivência na casa dos pais, levando em conta a sua forma singular de estar no mundo. A relação do pai com Vítor se definia por um afastamento, ao passo que a relação da mãe com o filho era pautada por exigências e expectativas, não reconhecendo as dificuldades e os limites do filho. Vítor respondia a isto de forma agressiva, o que fazia a mãe ter medo dele, impedindo-o de ficar em casa.

$\mathrm{O}$ atendimento à família de Vítor no CAPS teve prolongamento mesmo sem a presença dele. As palavras presença e ausência são muito significativas aqui, pois Vítor não estava exatamente ausente, já que estava o tempo todo presente na fala da mãe e essa é uma forma simbólica de presença, muitas vezes mais intensa que a própria presença física.

Nos momentos em que estava internado, Vítor conseguia circular pelo CAPS, colocando-se mais disponível para alguma intervenção possível, começando a participar de alguns atendimentos à família, situação que não durou muito tempo. Em algumas conversas com a terapeuta de referência, ele conseguiu dizer que queria ser ouvido, mas não junto com sua família, pois eles o tratavam como louco e sua mãe, mais uma vez, foi a responsável por sua internação. Contou que recebeu o diagnóstico de esquizofrênico quando adolescente e isso atrapalhou muito sua vida. Considerava tal diagnóstico um equívoco e há muito tempo lutava para revertê-lo, pedindo ajuda, inclusive, a organizações estrangeiras para quem costumava escrever cartas e mandar mensagens através da Internet. Pode-se perceber a importância da questão do diagnóstico para ele, na medida em que determina um certo lugar de existência no mundo. O diagnóstico ficou como uma marca, estigma decorrente do "Tu és isso". Existir como um esquizofrênico é insuportável para ele, então segue lutando para construir alguma forma de existência menos sofrida.

Vincular Vítor a alguma forma de tratamento era o nosso projeto e não o dele; seu pedido era simples: ele precisava falar sobre sentimentos, pois não tinha nada de louco, mas não queria falar disto ali naquele espaço de loucos. Esta fala de Vítor 


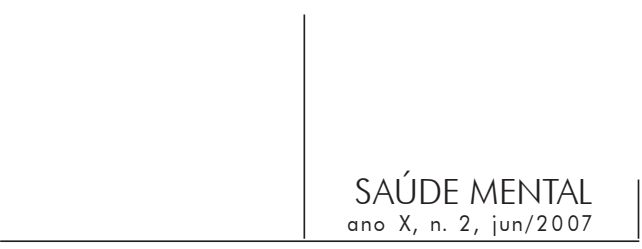

pode ser interpretada como um pedido de ajuda e poderia ter sido acolhido pela terapeuta de referência do caso. No entanto, a forma como o caso chegou ao CAPS tocou algum ponto de dificuldade da psicanalista, que não pôde acolher e escutar a fala de Vítor. Podemos pensar que tal impossibilidade que se apresentou do lado do analista foi percebida por Vítor, já que o psicótico é extremamente sensível à possibilidade e disponibilidade de acolhimento que vem do outro. Aos poucos, com muita delicadeza, fomos aprendendo a ouvir o que Vítor estava nos dizendo e criando condições para ele começar a freqüentar o CAPS. ${ }^{3}$

$\mathrm{Na}$ construção de um projeto de tratamento para o psicótico, fica claro a importância de escutarmos os limites e as aberturas que o próprio sujeito vai indicando. Como aponta Zenoni (2000), a função de secretário do alienado implica o acompanhamento do trabalho do sujeito psicótico, sendo um dos aspectos desta função seguir os caminhos que o sujeito indica. Neste sentido, não cabe ao psicanalista a função de interpretação, pois isso poderia comprometer a transferência e a possibilidade de tratamento. A interpretação pode levar a uma dimensão de enigma, podendo desenvolver um caráter persecutório para o sujeito, levando-o a se interrogar sobre o que o psicanalista quis lhe dizer. No caso de Vítor, qualquer abordagem, qualquer fala dirigida a ele o fazia sentir-se bastante perseguido e invadido. Ele deixava muito claro que ia indicar o tempo necessário para se chegar ao CAPS; restava à equipe ter paciência para aguardar esse momento. Isso, no entanto, só pôde ser elaborado no "só depois".

É importante lembrar que no desenvolvimento da clínica, e isso não se restringe à clínica da psicose, além dos limites e aberturas do sujeito, há também a posição do psicanalista e os limites de quem pretende sustentá-la.

É fundamental, portanto, problematizar neste ponto como se deu minha entrada no caso como terapeuta de referência no trabalho com a família, um contexto de um trabalho iniciado por uma equipe de profissionais de outra instituição. Ao refletirmos e escrevermos sobre o caso, percebemos que o significante da transferência aí é exclusão, já que houve uma transferência no trabalho com a família, e foi desta forma que a psicanalista foi incluída na transferência, pois já entrou no caso reproduzindo automaticamente o estigma trazido pela equipe que encaminhou o caso. Assim, foi colocada e se colocou num lugar na transferência que se manifestou pelo traço exclusão, iniciando um trabalho orientada por essa marca. Este parece ser efetivamente o traço do caso: Vítor é excluído da família e do tratamento, o pai é excluído da fala da mãe e da relação com o filho; não seria possível esse traço não aparecer na clínica do caso. Tal

3. Isto pôde se dar num segundo tempo, após a discussão do caso e o encaminhamento para outro profissional que assumiu o lugar de técnico de referência. 


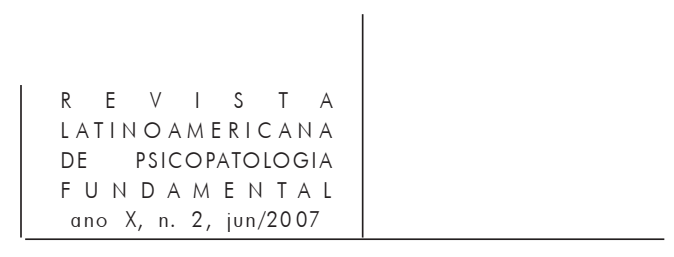

traço pertence ao caso, e justamente por isso acabou se transformando num estigma, numa marca, não permitindo que o caso fosse atendido por todos esses anos. De fato, no CAPS, iniciamos o atendimento deste caso, via família e houve uma transferência da família com a psicanalista e com o resto da equipe. Houve, por outro lado, um desejo da psicanalista de acompanhar o caso. No entanto, a possibilidade ou não de um desejo de escuta do sujeito surgir, a partir do desejo do analista, foi marcada por esse traço que já apareceu na maneira como o caso foi encaminhado. O desejo do analista não é um desejo qualquer entre tantos outros. É um desejo que depende do percurso de análise do próprio analista. Por isso, Lacan indica o seu surgimento na passagem de analisante a analista, ao final de uma análise.

Ao assumir o atendimento do caso me propus a enfrentar o que para mim já se apresentava como um desafio diferente dos outros casos com os quais me deparei até aquele momento. Iniciou-se, assim, um trabalho marcado pela descrença, o que a princípio não foi suficiente para definir uma desistência, pelo contrário. Insisti, e,na medida em que fui trabalhando em supervisão e em análise pessoal minhas questões, pude estabelecer um certo investimento no caso. No entanto, se por um lado ao trabalhar meus receios em supervisão e em análise pessoal consegui abrir algumas possibilidades de um trabalho com este caso, por outro, fui me dando conta de que cada vez acreditava menos na possibilidade de Vítor fazer algum tipo de laço transferencial. Acredito que no trabalho com psicóticos e com suas famílias, respectivamente, é necessário um grande investimento, e uma aposta, uma crença na possibilidade de que algo possa vir a se mover e se redirecionar. A delicadeza e o cuidado na apresentação de um caso a ser encaminhado para outra equipe é fundamental para a posterior condução do mesmo. Esse é o ponto importante a ser problematizado, pois é onde se dá o cruzamento entre o que é da esfera institucional e o que é da esfera de um trabalho individual do psicanalista na instituição de saúde mental.

Esse caso é emblemático da tensão que surge entre essas duas esferas, pois demonstra como a instituição pode atravessar o trabalho do psicanalista. Foi um caso atendido por duas equipes em parceria (a equipe do ambulatório central do IMAS que foi quem encaminhou o caso para o CAPS e a equipe do CAPS). Ao estar como referência do caso, a psicanalista assumiu um lugar responsável por escutar o discurso da família e de Vítor, no entanto, a disponibilidade e a possibilidade de investimento foram abaladas pelo estigma trazido pela instituição em relação a Vítor. Foi com base num amplo trabalho de análise pessoal e de supervisão pessoal e em equipe que foi possível à analista se dar conta de que o que se apresentava ali era um limite clínico, um limite colocado pelo contexto em que o caso chegou ao CAPS. Houve aí um insuportável, um mal-estar da parte da analista que, ao invés de perpetuar a repetição, provocou uma reviravolta no 
atendimento do caso, ao fazer uma intervenção, um ato, o ato de sair do caso e encaminhá-lo para outro profissional que assumiu o lugar de referência. Nesse momento deu-se uma interrupção do processo que vinha se desenvolvendo até então em relação ao caso Vítor e, ao invés de levar adiante a descrença, pela primeira vez, em anos, o caso pôde ser visto de outra forma. $\mathrm{O}$ ato de sair do caso, entretanto, não ocorreu sem um trabalho de elaboração e de reflexão junto à equipe, e foi isto que propiciou o posterior avanço do mesmo. A experiência vivida aí aponta para os limites da clínica e falar dos limites é importante para a realização da própria clínica.

A exposição deste caso e dos problemas que envolveram o contexto clínico em que ele se desenvolveu evidencia as dificuldades do trabalho com a psicose, principalmente na instituição de saúde mental onde, muitas vezes, herda-se formas de abordagem e encaminhamentos tradicionais que chegam a inviabilizar um possível tratamento. Foi marcado pelo estigma de ser intratável que o paciente chegou ao CAPS encaminhado pela equipe do ambulatório central do IMAS. O que pôde se produzir no CAPS foi a construção e a abertura de novas formas e possibilidades de acolhimento a Vítor, propiciando um espaço de existência a partir de sua singularidade.

Levando em conta os dois casos apresentados, é importante neste momento fazer uma reflexão sobre a clínica da psicose no contexto institucional. Se a instituição é necessária para acolher e tratar casos graves, por sua vez impõe configurações e limites que são difíceis de romper. No primeiro caso a moldura institucional não era indispensável, uma vez que o desenvolvimento do caso poderia ter se dado no consultório do psicanalista. No segundo caso, por sua vez, a marca da instituição esteve presente desde o início determinando seus desdobramentos. Acrescente-se a isso o fato de que qualquer trabalho clínico, seja no consultório ou na instituição, depende do que o psicanalista faz dele e de seus limites, sendo sua implicação na situação de transferência sustentada pelo desejo do analista determinante de uma posição fundamental para que o processo analítico se efetive. O desejo do analista, desta forma, apóia-se em um saber esvaziado, um não-saber e é neste sentido que ele se liga à questão ética da prática analítica escapando de um registro da vontade, de um querer ser analista, sendo justamente na instituição e na clínica da psicose que ele é mais colocado à prova.

\section{Referências}

Allouch, Jean. Marguerite ou a Aimée de Lacan. Rio de Janeiro: Companhia de Freud, 1997. 


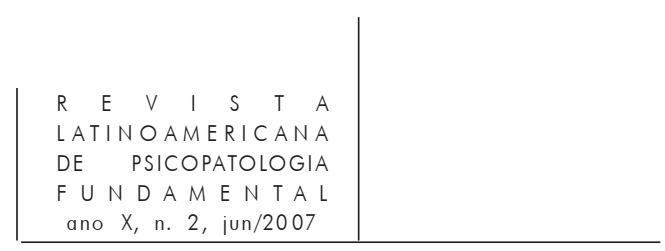

Amarante, Paulo. Loucos pela vida. Rio de Janeiro: Fiocruz, 1998.

Freud, Sigmund (1911). Notas psicanalíticas sobre um relato autobiográfico de um caso de paranóia - caso Schreber. In: Edição Standard Brasileira das Obras Psicológicas Completas de Sigmund Freud. Rio de Janeiro: Imago, 1996. v. XII.

(1917[1916-1917]). A teoria da libido e o narcisismo - Conferência XXVI. In: Edição Standard Brasileira das Obras Psicológicas Completas de Sigmund Freud. Rio de Janeiro: Imago, 1996. v. XVI.

(1917[1916-1917]). Transferência - Conferência XXVII. In: Edição Standard Brasileira das Obras Psicológicas Completas de Sigmund Freud. Rio de Janeiro: Imago, 1996. v. XVI.

LaCAN, Jacques (1955-1956). O seminário. Livro 3. As psicoses. Rio de Janeiro: Jorge Zahar, 1985.

1992.

(1960-1961). O seminário. Livro 8. A transferência. Rio de Janeiro: Jorge Zahar,

(1964). O seminário. Livro 11. Os quatro conceitos fundamentais da psicanálise. Rio de Janeiro: Jorge Zahar, 1988.

Da psicose paranóica em suas relações com a personalidade. Rio de Janeiro: Forense Universitária, 1987.

Zenoni, Alfredo. Psicanálise e instituição. Abrecampos, Revista de Saúde Mental do Instituto Raul Soares, Belo Horizonte: Rede FHEMIG, ano 1, n. 0, 2000.

\section{Resumos}

El presente artículo trata de hacer una reflexión sobre la clínica de la psicosis en el campo de la salud mental a través de la transferencia y de aquello que Lacan denominó deseo del analista. Para eso, son trabajados dos fragmentos de casos clínicos atendidos en una institución de salud mental, el CAPS Clarice Lispector, situado en la ciudad de Río de Janeiro, en el territorio del instituto IMAS-Nise da Silveira. A partir del análisis de los dos casos presentados, la discusión del trabajo gira en torno de una reflexión sobre la clínica de la psicosis en el contexto institucional y en el lugar ocupado por el psicoanalista en esta clínica.

Palabras claves: Clínica de la psicosis, transferencia, deseo del analista, institución

Cet article cherche à réfléchir sur la clinique de la psychose dans le domaine des Services de Santé Mentale, par le moyen de la notion de transfert et de ce que Jacques 
Lacan a nommé le désir de l'analyste. À cette fin, l'article examine des fragments de deux cas cliniques du CAPS Clarice Lispector (Institut IMAS Nise da Silveira, Rio de Janeiro, Brésil). À partir de l'analyse des deux cas cités, l'article discute la réflexion sur la situation de la clinique de la psychose dans un contexte institutionnel et sur la place qu'occupe le psychanalyste dans l'ensemble de cette clinique.

Mots clés: Clinique de la psychose, transfert, désir de l'analyste, institution

This article presents a reflection on clinical work with psychosis in the field of the mental health through transference and through what Lacan called the analyst's desire. The article presents excerpts from two case studies seen in a mental health care institution, the Clarice Lispector Mental Health Center, at the Nise da Silveira Institute in Rio de Janeiro, Brazil. From the analysis of the two cases presented, a discussion ensues about clinical work with psychosis in an institutional context and about the role played by the psychoanalyst in that clinic.

Key words: Clinical work with psychosis, transference, analyst's desire, institution

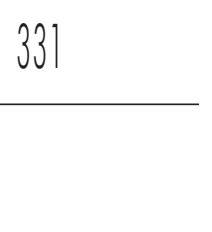

Versão inicial recebida em dezembro de 2006

Versão revisada recebida em março de 2007 